\title{
The Behaviour of Radionuclides in Gas Adsorption Chromatographic Processes with Superimposed Chemical Reactions (Chlorides)*
}

\author{
By B. Eichler \\ Paul Scherrer Institut, CH-5232 Villigen PSI, Switzerland
}

(Received May 12, 1995; revised July 17, 1995)

\author{
Thermochromatography / Gaschromatography / \\ Dissociative adsorption / Substitutive adsorption / \\ Radionuclides / Chlorides / Adsorption enthalpy / \\ Adsorption entropy
}

\begin{abstract}
Thermochemical relationships are derived describing the gas adsorption chromatographic transport of carrier-free radionuclides. Especially, complex adsorption processes such as dissociative, associative and substitutive adsorption are dealt with.

The comparison of experimental with calculated data allows the determination of the type of adsorption reaction, which is the basis of the respective gas chromatographic process.

The behaviour of carrier-free radionuclides of elements $\mathrm{Pu}$, $\mathrm{Ce}, \mathrm{Ru}, \mathrm{Co}$ and $\mathrm{Cr}$ in thermochromatographic experiments with chlorinating carrier gases can be described as dissociative adsorption of chlorides in higher oxidation states.

The gas adsorption chromatographic transport of $\mathrm{Zr}$ with oxygen and chlorine containing carrier gas is shown to be a substitutive adsorption process.

The consequences of superimposed chemical reactions on the interpretation of results and the conception of gas adsorption chromatographic experiments with carrier-free radionuclides in isothermal columns and in temperaure gradient tubes is discussed.
\end{abstract}

\section{Introduction}

Gas adsorption chromatographic processes are often used to separate and characterize radionuclides and their compounds. For this purpose isothermal columns as well as columns with an axial temperature gradient are employed.

The description of the transport mechanism in chromatographic columns usually employs the model of ideal linear gas chromatography $[1,2]$. The description of the process assumes, among other things, that the chemical state of the particles in the volatilization, transport, and deposition processes remains unaltered.

This assumption is linked with the thermodynamic stability of substances in the temperature regime of the respective experiment. However, in many cases this presumption is not fulfilled for instance in the trans-

\footnotetext{
* Presented at the Symposium of the German Nuclear Chemistry Group at Berlin, September 1994
}

port reactions of iridium oxides and hydroxides with oxygen-containing carrier gases [3].

In this work, some thermochemical fundamentals for an approximate description of the transport mechanism in the temperature gradient tube with chlorinated carrier gases are derived. Experimental results are discussed which, up to now, could not be interpreted unambiguously.

It is the objective of this work to evaluate the most probable reaction type of the adsorption chromatographic transport mechanism in the gradient tube and to describe complex, adsorption chromatographic processes with simple thermochemical relationships.

\section{Fundamentals and basic data}

The description of the transport mechanism in the temperature gradient tube employs usually a series of simplifications and approximations. The conditions, under which the model of ideal linear gas chromatography are explained in [4]. For processes with carrier-free radionuclides, these conditions are satisfactorily fulfilled with regard to the degree of coverage $[1,2]$.

The description is based on the ideal assumption that the equilibration of all subprocesses occurs quickly and completely. In all other cases, one has to assume that the species involved in the equilibrium separate partially or completely and obey as "independent" (non-equilibrium) species the law of chromatographic transport.

Furthermore, it is assumed that only one well defined chemical reaction is superimposed on the chromatographic process. However, in real systems, parallel or subsidiary reactions are possible, as well as a temperature-dependent sequence of various reactions in the temperature gradient tube.

The real gas adsorption chromatographic process is essentially determined by the migration velocity of the substance zones in the region of the deposition temperature in the temperature gradient tube, or the retention temperature in isothermal columns. For this reason, thermochemical calculations are carried out at standard conditions ignoring the temperature dependence of thermodynamic state functions. For a number 
of substances in unusual oxidation states even the standard thermodynamic state functions can only be derived approximately.

The evaluation of experimental results has to consider the approximative character of relationships describing the transport mechanism, as well as the errors of the experimental and thermochemical data. Also, the possibility of kinetic hindrance of elementary processes must be taken into account.

A large number of thermochromatographic experiments with chlorine as carrier gas has been reported [5] and an empirical correlation of the adsorption enthalpies of carrier-free chlorides on quartz surfaces with the respective standard enthalpies of sublimation has been derived:

$$
-\Delta H_{\text {ads }}=(0.655 \pm 0.042) * \Delta H_{\text {subl }}+(18.0 \pm 8.8) \text {. }
$$

In this correlation, only those elements were included whose chemical state in the $\mathrm{Cl}_{2} / \mathrm{CCl}_{4}$ carrier gas was well established. For the excluded elements the chemical state could not be established or the results clearly contradicted expectations. Significant deviations of a thermochromatographic result from the correlation (1) can be an indication for a complex adsorption process. Such processes can also lead to multiple peaks or to peak broadening.

Independently from these empirical observations, data about the suspected mechanism can also be inferred from examination of thermochemical data. This hypothesis must be further investigated when the supposed reaction is thermodynamically favoured.

Possible types of reactions for processes, superimposed on the gas adsorption chromatographic process are dissociation, its reverse, association, and substitution. In the following, simple examples and the associated thermochemical relationships for these reaction equilibria are given:

- Dissociative adsorption:

$$
\begin{aligned}
\mathrm{MCl}_{x}(\mathrm{~g}) \leftrightarrow & \mathrm{MCl}_{x-1}(\mathrm{ads})+1 / 2 \mathrm{Cl}_{2}(\mathrm{~g}) \\
\Delta H_{\text {diss.ads }}= & \Delta H \mathrm{MCl}_{x-1}(\mathrm{~g})+\Delta H_{\mathrm{ads}} \mathrm{MCl}_{x-1} \\
& -\Delta H \mathrm{MCl}_{x}(\mathrm{~g}) \\
\Delta S_{\text {dis. ads }}= & \mathrm{S} \mathrm{MCl}{ }_{x-1}(\mathrm{~g})+\Delta S_{\text {ads }} \mathrm{MCl}_{x-1} \\
& +1 / 2 \mathrm{~S} \mathrm{Cl}_{2}(\mathrm{~g})-\mathrm{S} \mathrm{MCl} \mathrm{MC}_{x}(\mathrm{~g})
\end{aligned}
$$

- Associative adsorption:

$$
\begin{aligned}
\mathrm{MCl}_{x}(\mathrm{~g})+ & 1 / 2 \mathrm{Cl}_{2}(\mathrm{~g}) \leftrightarrow \mathrm{MCl}_{x+1}(\text { ads }) \\
\Delta H_{\text {ass.ads }}= & \Delta H \mathrm{MCl}_{x+1}(\mathrm{~g})+\Delta H_{\text {ads }} \mathrm{MCl}_{x+1} \\
& -\Delta H \mathrm{MCl}_{x}(\mathrm{~g}) \\
\Delta S_{\text {ass.ads }}= & \mathrm{S} \mathrm{MCl}_{x+1}(\mathrm{~g})+\Delta S_{\text {ads }} \mathrm{MCl}_{x+1} \\
& -1 / 2 \mathrm{~S} \mathrm{Cl}_{2}(\mathrm{~g})-\mathrm{S} \mathrm{MCl}_{x}(\mathrm{~g})
\end{aligned}
$$

- Substitutive adsorption:

$$
\begin{aligned}
\mathrm{MCl}_{x}(\mathrm{~g})+ & 1 / 2 \mathrm{O}_{2}(\mathrm{~g}) \leftrightarrow \mathrm{MOCl}_{x-2}(\mathrm{ads})+\mathrm{Cl}_{2}(\mathrm{~g}) \\
\Delta H_{\text {subst.ads }}= & \Delta H \mathrm{MOCl}_{x-2}(\mathrm{~g})+\Delta H_{\text {ads }} \mathrm{MOCl}_{x-2} \\
& -\Delta H \mathrm{MCl}_{x}(\mathrm{~g})
\end{aligned}
$$

$$
\begin{aligned}
\Delta S_{\text {subst.ads }}= & \mathrm{S} \mathrm{MOCl}_{x-2}(\mathrm{~g}) \\
& +\Delta S_{\text {ads }} \mathrm{MOCl}_{x-2}+\mathrm{S} \mathrm{Cl}_{2} \\
& -\mathrm{S} \mathrm{MCl}_{x}(\mathrm{~g})-1 / 2 \mathrm{~S} \mathrm{O}_{2}
\end{aligned}
$$

For thermochromatographic processes with invariable particles, a connection between the experimental parameters and the thermodynamic state function of the adsorption process was derived in [2].

The thermodynamic state functions (2)-(7) must be included in the derivation of this relationship. The following corrected partitioning coefficients for the above mentioned adsorption reactions are obtained:

$$
\begin{aligned}
& k_{i, \text { diss.ads }}=\frac{a \cdot\left(c^{\circ} \mathrm{Cl}_{2}(\mathrm{~g})\right)^{1 / 2} \cdot 1 \mathrm{~cm}}{v\left(c \mathrm{Cl}_{2}(\mathrm{~g})\right)^{1 / 2}} \cdot K_{\mathrm{diss.ads}} \\
& k_{i, \text { ass.ads }}=\frac{a \cdot\left(c \mathrm{Cl}_{2}(\mathrm{~g})\right)^{1 / 2} \cdot 1 \mathrm{~cm}}{v\left(c^{\circ} \mathrm{Cl}_{2}(\mathrm{~g})\right)^{1 / 2}} \cdot K_{\text {ass.ads }}
\end{aligned}
$$

and

$$
\begin{aligned}
& k_{i, \text { substads }} \\
& =\frac{a\left(c \mathrm{O}_{2}(\mathrm{~g})\right)^{1 / 2} \cdot\left(c^{\circ} \mathrm{Cl}_{2}(\mathrm{~g})\right)^{1 / 2} \cdot 1 \mathrm{~cm}}{v\left(c \mathrm{Cl}_{2}(\mathrm{~g})\right)} \cdot K_{\text {subst.ads }}
\end{aligned}
$$

Here

$k_{i, \text { index }}$ : corrected partition coefficient of the indicated adsorption reaction

$a\left[\mathrm{~cm}^{2} / \mathrm{cm}\right]: \quad$ surface area per unit length of co$v\left[\mathrm{~cm}^{3} / \mathrm{cm}\right]: \quad \begin{array}{ll}\text { free volume per unit length of co- }\end{array}$ lumn

$c A(\mathrm{~g})\left[\mathrm{cm}^{-3}\right]: \quad$ concentration of species $A$

$c^{\circ} A(\mathrm{~g})\left[\mathrm{cm}^{-3}\right]:$ standard concentration of species $A$ $\left(c^{\circ}=2.6793 \cdot 10^{19} \mathrm{~cm}^{-3}\right)$

$K_{\text {index }}: \quad$ dimensionless equilibrium constant of the indicated adsorption reaction.

The determination of the standard states was explained in [3]. According to [2] and with Eqs. (8)-(10) it follows:

$$
\begin{aligned}
\frac{t \cdot v^{\circ} \cdot g \cdot f(c)}{a \cdot T^{\circ} \cdot \exp \left(\frac{\Delta S_{\text {index }}}{R}\right)}= & E i^{*}\left(\frac{-\Delta H_{\text {index }}}{R T}\right) \\
& -E i^{*}\left(\frac{-\Delta H_{\text {index }}}{R T_{s}}\right)
\end{aligned}
$$

$v^{\circ}\left[\mathrm{cm}^{3} / \mathrm{s}\right]:$

$t$ [s]:

$g\left[\mathrm{~K} \mathrm{~cm}^{-1}\right]$ :

$T^{\circ}[\mathrm{K}]$ :

$T[\mathrm{~K}]:$

$T_{s}[\mathrm{~K}]$ :

$\Delta H_{\text {index }}[\mathrm{J} / \mathrm{mol}]:$

$\Delta S_{\text {index }}[\mathrm{J} / \mathrm{mol} \cdot \mathrm{K}]:$

$R[\mathrm{~J} / \mathrm{mol} \cdot \mathrm{K}]:$

$E i^{*}(x)$ : gas flow rate duration of the experiment temperature gradient standard temperature deposition temperature starting temperature standard enthalpy of the indicated reaction

standard enthalpy of the respective reaction gas constant integral exponential function of $x$ 
The following relations hold for $f(c)$ :

index: ads.

$$
f(c)=(1 \mathrm{~cm})^{-1}
$$

index: diss.ads.

$$
f(c)=\frac{\left(c \mathrm{Cl}_{2}(\mathrm{~g})\right)^{1 / 2}}{\left(c^{\circ} \mathrm{Cl}^{2}(\mathrm{~g})\right)^{1 / 2} \cdot 1 \mathrm{~cm}}
$$

index: ass.ads.

$$
f(c)=\frac{\left(c^{\circ} \mathrm{Cl}_{2}(\mathrm{~g})\right)^{1 / 2}}{\left(c \mathrm{Cl}_{2}(\mathrm{~g})\right)^{1 / 2} \cdot 1 \mathrm{~cm}}
$$

index: subst.ads.

$$
f(c)=\frac{\left(c \mathrm{Cl}_{2}(\mathrm{~g})\right)}{\left(c^{\circ} \mathrm{Cl}_{2}(\mathrm{~g})\right)^{1 / 2} \cdot\left(c \mathrm{O}_{2}(\mathrm{~g})\right)^{1 / 2} \cdot 1 \mathrm{~cm}}
$$

In the following analysis of experimental literature results, the required values for the adsorption enthalpies of chlorides and oxychlorides on quartz surfaces were estimated with the empirical correlation (Eq. (1)).

The calculation of the standard adsorption entropy of chlorides was carried out on the basis of the model of mobile adsorption [2]. The data base for the remaining thermodynamic state functions is given in Refs. [6-15].

For some quantities no data was available and approximate values had to be assessed. The standard entropy of gaseous chromium tetrachloride was calculated from the standard entropy of formation of this compound $[10,14]$.

$$
S \mathrm{CrCl}_{4}(\mathrm{~g})=(373)(\mathrm{J} / \mathrm{K} \mathrm{mol}) \text {. }
$$

The standard entropy of gaseous cerium tetrachloride was estimated on the basis of an empirical relationship:

$$
S \mathrm{MCl}_{4}(\mathrm{~g})=A \lg M\left(\mathrm{XCl}_{4}\right)+B
$$

with $M=$ molecular weight:

$$
S \mathrm{CeCl}_{4}(\mathrm{~g})=(381)(\mathrm{J} / \mathrm{K} \mathrm{mol}) \text {. }
$$

The standard entropy of gaseous $\mathrm{ZrOCl}_{2}$ was estimated from the characteristic ratio for titanium compounds:

$$
\frac{S \mathrm{TiOCl}_{2}(\mathrm{~g})}{S \mathrm{TiCl}_{4}(\mathrm{~g})}=0.90449 \text {. }
$$

Using these values and the known values for $S \mathrm{ZrCl}_{4}(\mathrm{~g}), S \mathrm{ZrOCl}_{2}(\mathrm{~g})=(332.6)(\mathrm{J} / \mathrm{K} \mathrm{mol})$ was determined.

The atomic enthalpy of formation of $\mathrm{ZrOCl}_{2}(\mathrm{~g})$ were estimated from the atomic enthalpies of formation of the tetrachloride and the dioxide in two ways:

i) as the sum of the atomic enthalpy of formation of the gaseous $\mathrm{ZrO}$ and the bonding enthalpy of 2 chlorine atoms in $\mathrm{ZrCl}_{4}$ or

ii) as the sum of the atomic enthalpy of formation of the gaseous $\mathrm{ZrCl}_{2}$ and the bonding enthalpy of one oxygen atom in $\mathrm{ZrO}_{2}$, respectively.

The atomic enthalpy of formation of solid $\mathrm{ZrOCl}_{2}$ was calculated from experimental results of thermal
Table 1. Thermodynamic state functions of the adsorption reactions (calculated with literature data [6-15] and estimates (this work))

\begin{tabular}{lcc}
\hline Index & $\begin{array}{c}-\Delta H_{\text {index }} \\
(\mathrm{kJ} / \mathrm{mol})\end{array}$ & $\begin{array}{c}-\Delta S_{\text {index }} \\
(\mathrm{J} / \mathrm{K} \mathrm{mol})\end{array}$ \\
\hline $\mathrm{PuCl}_{3}$ ads. & 220.00 & 168.45 \\
$\mathrm{PuCl}_{4}$ ads. & 122.12 & 168.86 \\
$\mathrm{PuCl}_{4}$ diss.ads. & 79.38 & 101.72 \\
$\mathrm{CrCl}_{3}$ ads. & 187.90 & 167.33 \\
$\mathrm{CrO}_{2} \mathrm{Cl}_{2}$ ads. & 51.70 & 167.24 \\
$\mathrm{CrCl}_{4}$ diss.ads. & 45.00 & $(66.64)$ \\
$\mathrm{RuCl}_{3}$ ads. & 173.96 & 165.57 \\
$\mathrm{RuCl}_{4}$ diss.ads. & 63.76 & 64.52 \\
$\mathrm{CeCl}_{3}$ ads. & 241.36 & 166.13 \\
$\mathrm{CeCl}_{4}$ diss.ads. & {$[147]$} & $(106.90)$ \\
$\mathrm{CoCl}_{2}$ ads. & 166.03 & 163.24 \\
$\mathrm{CoCl}_{3}$ diss.ads. & 86.48 & 89.59 \\
$\mathrm{ZrCl}_{4}$ ads. & 90.36 & 165.42 \\
$\mathrm{ZrOCl}_{2}$ ads. & $(346)$ & 164.30 \\
$\mathrm{ZrCl}_{4} / \mathrm{ZrOCl}{ }_{2}$ subst.ads. & $63.93)$ & $(79.02)$ \\
$\mathrm{AgCl}$ ads. & 161.84 & 162.37 \\
$\mathrm{Ag} \mathrm{ass.ads}$ & 69.34 & 200.66 \\
\hline
\end{tabular}

dissociation [26] and the following average values were obtained:

$$
\begin{aligned}
& \Delta H^{*} \mathrm{ZrOCl}_{2}(\mathrm{~g})=(1681)(\mathrm{kJ} / \mathrm{mol}) \text { and } \\
& \Delta H^{*} \mathrm{ZrOCl}_{2}(\mathrm{~s})=(2182)(\mathrm{kJ} / \mathrm{mol}) \text { and thus } \\
& \Delta H \mathrm{ZrOCl}_{2} \text { (subl) }=(501)(\mathrm{kJ} / \mathrm{mol}) \text { resulted. }
\end{aligned}
$$

In Table 1 the thermodynamic state functions of the adsorption processes calculated with Equations (2)-(7) are listed. When the above mentioned approximations were used, the numerical information was placed in round brackets. If the values were calculated by means of experimental results, the numerical values are given in square brackets.

\section{Deriving the type of the adsorption reaction from the results of thermochromatographic experiments}

\subsection{Dissociative adsorption}

The result of a thermochromatographic experiment is the measured deposition temperature $T$ of a radioactive substance (position of the activity maximum in the temperature gradient tube), which depends on several experimental parameters $\left(t, g, v^{\circ}, a, T_{s}\right.$; see Equation (11)).

In order to empirically determine the type of the reaction and thus also the chemical state of the radionuclide in the adsorbed and in the gaseous state, alternative analyses procedures may be applied.

First, the theoretical dependence between adsorption enthalpy and deposition temperature, assuming stable, invariable species, was calculated (Eq. (11)) for possible chemical states. In Figures 1-3, these curves are marked with the formula of the compound. The calculation and presentation of alternative types of reaction were performed in an analogous manner. 
The measured deposition temperature of a thermochromatographic experiment is plotted with the abscissa $T$ (deposition temperature) and the ordinate log $\Delta E i^{*}(x)$ (Eq. (11) left hand side). This value is determined by the experimental parameters and the adsorption entropy.

The latter is calculated according to the selected type of reaction: either for simple adsorption of invariable species or for complex adsorption reactions (Eqs. (3), (5) and (7)).

In this manner, the type of reaction is obtained which explains best a thermochromatographic result.

The theoretical curves (Eq. (11)) for the adsorption of $\mathrm{PuCl}_{3}$ and $\left(\mathrm{PuCl}_{4}\right)$ are shown in Figure 1a. These curves refer to the adsorption reactions

$$
\mathrm{PuCl}_{3} \text { (g) } \mathrm{PuCl}_{3} \text { (ads) }
$$

and

$$
\left(\mathrm{PuCl}_{4}\right)(\mathrm{g}) \leftrightarrow\left(\mathrm{PuCl}_{4}\right)(\mathrm{ads})
$$

The calculated curve for the adsorption reaction

$$
\mathrm{PuCl}_{4}(\mathrm{~g}) \leftrightarrow \mathrm{PuCl}_{3} \text { (ads) }+1 / 2 \mathrm{Cl}_{2}(\mathrm{~g})
$$

is designated with diss.ads.

Experiments were carried out with $\mathrm{Ar} / \mathrm{CCl}_{4}$ as well as with $\mathrm{Cl}_{2} / \mathrm{CCl}_{4}$ carrier gas [1]. When using $\mathrm{Ar} / \mathrm{CCl}_{4}$ as carrier gas, obviously $\mathrm{PuCl}_{3}$ is transported and deposited at relatively high temperatures $\left(\sim 825^{\circ} \mathrm{K}\right)$. The experimental result is in satisfactory agreement with the $\mathrm{PuCl}_{3}$ curve. (The experimental deposition temperature is lower than the calculated value. Apparently with an empty tube as chromatographic column, the adsorption equilibrium is not fully reached.)

The experiments with $\mathrm{Cl}_{2} / \mathrm{CCl}_{4}$ carrier gas lead to significantly lower deposition temperatures. This result cannot be considered as an adsorption process of volatile $\mathrm{PuCl}_{4}$, because $\mathrm{PuCl}_{4}$ exists only in the gas phase, but not as a pure compound in the condensed state [25].

Reaction (12), the dissociative adsorption, can be assumed with a high degree of confidence as the adsorption chromatographic process.

The results for the system $\mathrm{CrCl}_{3}-\mathrm{Cl}_{2}-\mathrm{CrCl}_{4}-$ $\left(\mathrm{CrO}_{2} \mathrm{Cl}_{2}\right)$ are given in Fig. 1b. The curves for the adsorption of $\mathrm{CrCl}_{3}, \mathrm{CrO}_{2} \mathrm{Cl}_{2}$ and for the dissociative adsorption process (analogous [27]):

$$
\mathrm{CrCl}_{4} \leftrightarrow \mathrm{CrCl}_{3} \text { (ads) }+1 / 2 \mathrm{Cl}_{2}
$$

are shown.

The experiment [5] was carried out with $\mathrm{Cl}_{2} / \mathrm{CCl}_{4}$ carrier gas. Because of the low deposition temperature, the direct transport of $\mathrm{CrCl}_{3}$ can be excluded. Within the limits of accuracy of Eqs. (2), (3) and (11) dissociative adsorption according to Eq. (13) can be assumed.

In the case of oxygen contamination of the carrier gas, the formation of $\mathrm{CrO}_{2} \mathrm{Cl}_{2}$ is possible. The measured deposition temperature is consistent with simple non complex adsorption of $\mathrm{CrO}_{2} \mathrm{Cl}_{2}$. However, this process is rather unlike because of the presence of $\mathrm{CCl}_{4}$ as a powerful oxygen getter.
For cobalt chlorides, there also exists a chloride in the gas phase in a high oxidation state, which does not exist in the pure condensed phase [5]. Figure 1c shows the corresponding curves for the adsorption of $\mathrm{CoCl}_{2}$ and the dissociative adsorption:

$$
\mathrm{CoCl}_{3}(\mathrm{~g}) \leftrightarrow \mathrm{CoCl}_{2} \text { (ads) }+1 / 2 \mathrm{Cl}_{2} \text { (g) }
$$

The experimental data is in better agreement with this type of reaction.

A convincing interpretation is also possible in the case of thermochromatographic experiments with ruthenium in $\mathrm{Cl}_{2} / \mathrm{CCl}_{4}$ carrier gas [5] (Figure 1d). The basis of the gas adsorption chromatographic process is a dissociative mechanism:

$$
\mathrm{RuCl}_{4}(\mathrm{~g}) \leftrightarrow \mathrm{RuCl}_{3} \text { (ads) }+1 / 2 \mathrm{Cl}_{2} \text {. }
$$

There are contradictory results on the transport mechanism of $\mathrm{Ce}$ chlorides by chlorinating carrier gases. In volatilization experiments of macroscopic quantities of $\mathrm{CeCl}_{3}$ in the chlorine stream [17], no transport mechanism due to a higher chloride was found nor were there traces of a higher chloride in the deposit.

Also, experiments in the temperature gradient tube with Ce-containing ${ }^{144} \mathrm{Ce}$ tracer [18] showed no indication of a transport mechanism involving $\mathrm{CeCl}_{4}$.

In experiments with carrier-free radionuclides of cerium $[1,5]$, lower deposition temperatures results compared to typical lanthanides [19].

In Figure 1e these results are characterized as simple adsorption and dissociative adsorption:

$$
\mathrm{CeCl}_{4}(\mathrm{~g}) \leftrightarrow \mathrm{CeCl}_{3} \text { (ads) }+1 / 2 \mathrm{Cl}_{2}(\mathrm{~g})
$$

In Ref. [20] two adsorption peaks were reported indicating two chemical states.

Thermochemical data is only available for $\mathrm{CeCl}_{3}$. The theoretical curve for $\mathrm{CeCl}_{3}$ is shown in Figure 1e.

The first deposition peak at high temperature, where also the remaining lanthanide-chlorides are deposited [20], can be attributed to $\mathrm{CeCl}_{3}$. The second deposition peak at low temperature is the result of a dissociative adsorption mechanism, like the results in Refs. [1] and [5].

For this case, two theoretical curves were calculated in order to include all experimental values. The weighted average for the dissociative adsorption process yielded a standard enthalpy of

$$
\Delta H \mathrm{CeCl}_{4} \text { (diss.ads.) }=[147 \pm 10](\mathrm{kJ} / \mathrm{mol}) \text {. }
$$

With Eq. (2) the standard enthalpy of formation of gaseous $\mathrm{CeCl}_{4}$ can be determined:

$$
\Delta H \mathrm{CeCl}_{4}(\mathrm{~g})=[811 \pm 30](\mathrm{kJ} / \mathrm{mol})
$$

and the dissociation enthalpy for the process:

$$
\mathrm{CeCl}_{4}(\mathrm{~g}) \leftrightarrow \mathrm{CeCl}_{3}(\mathrm{~g})+\mathrm{Cl}(\mathrm{g}),
$$

$\Delta H_{\text {diss }} \mathrm{CeCl}_{4}(\mathrm{~g})=[215 \pm 30](\mathrm{kJ} / \mathrm{mol})$.

$\mathrm{CeCl}_{4}(\mathrm{~g})$ is less stable compared to $\mathrm{PuCl}_{4}(\mathrm{~g})$ (see Table 1). For this reason the gas phase transport with $\mathrm{Cl}_{2}$ is less "productive" than for plutonium. This also explains why the transport mechanism involving 

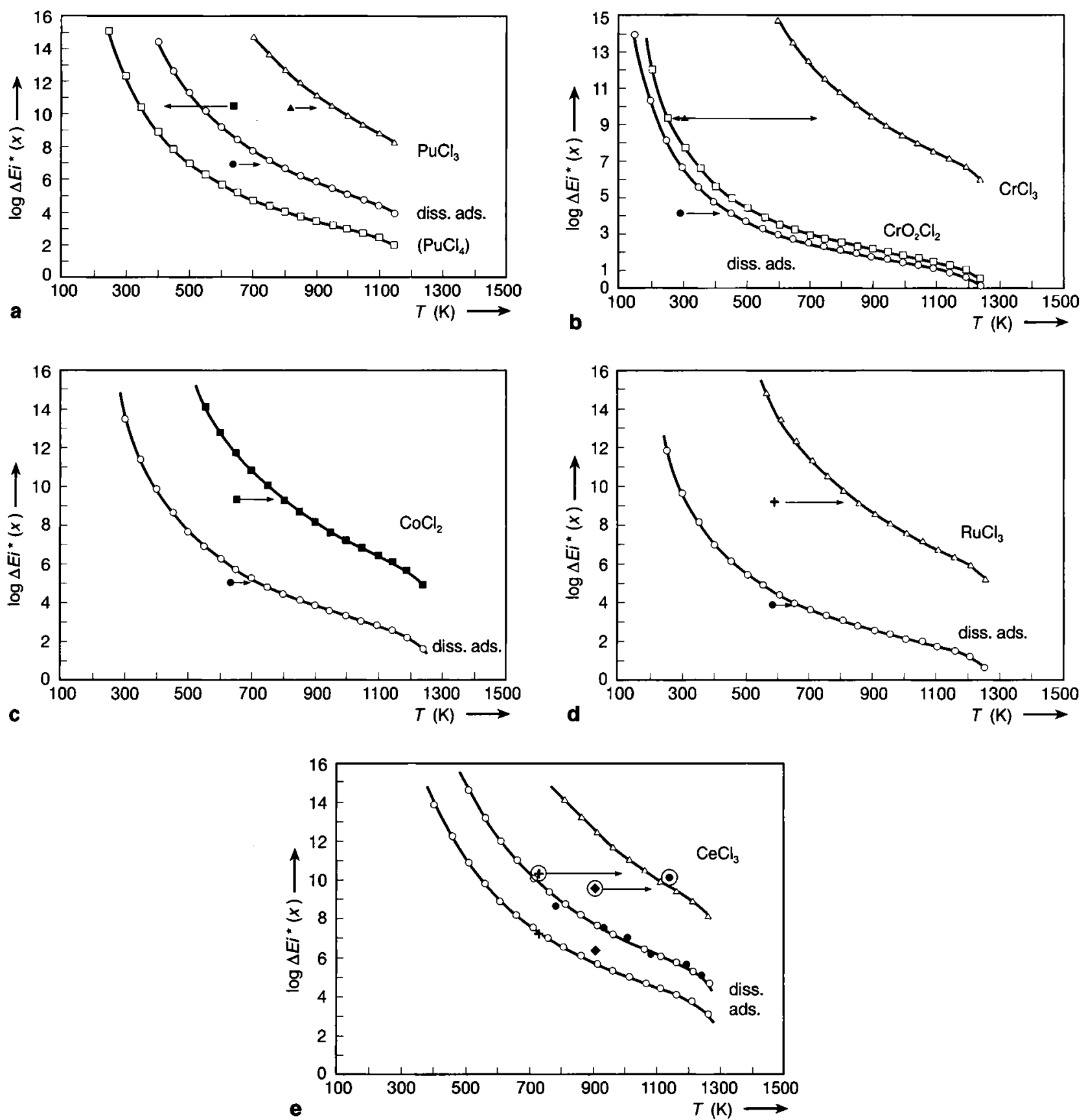

Fig. 1. Deposition temperatures in thermochromatographic columns - comparison between experimental and calculated data for simple or dissociative adsorption reactions. a) $\mathrm{PuCl}_{3}-\mathrm{PuCl}_{4}[1]: \Delta T$ : experimental deposition temperature in $\mathrm{Ar} / \mathrm{CCl}_{4} \mathrm{carrier}$ gas, $\Delta E i^{*}(x)$ : calculated with $\Delta S_{\text {ads }}$ for simple adsorption of $\mathrm{PuCl}_{3} ; \mathrm{T}$ : experimental deposition temperature in $\mathrm{Cl}_{2} / \mathrm{CCl}_{4}$ carrier gas, $\Delta E i^{*}(x)$ : calculated with $\Delta S_{\text {ads }}$ for simple adsorption of $\left(\mathrm{PuCl}_{4}\right) ; T$ : experimental desorption temperature in $\mathrm{Cl}_{2} / \mathrm{CCl}_{4}$ carrier gas, $E i^{*}(x)$ : calculated with $\Delta S_{\text {diss.ads }}$ for dissociative adsorption of $\mathrm{PuCl}_{4}$. b) $\mathrm{CrCl}_{3}-\mathrm{CrCl}_{4}$ [5]: $\Delta T$ : experimental deposition temperature in $\mathrm{Cl}_{2}-\mathrm{CCl}_{4}$ carrier gas, $\Delta E i^{*}(x)$ : calculated with $\Delta S_{\text {ads }}$ for simple adsorption of $\mathrm{CrCl}_{3}$ or $\mathrm{CrO}_{2} \mathrm{Cl}_{2} ; T$ : experimental deposition temperature in $\mathrm{Cl}_{2} / \mathrm{CCl}_{4}$ carrier gas, $\Delta E i^{*}(x)$ : calculated with $\Delta S_{\text {diss.ads }}$ for dissociative adsorption of $\mathrm{CrCl}_{4}$. c) $\mathrm{CoCl}_{2}-\mathrm{CoCl}_{3}$ [5]:

- T: experimental deposition temperature in $\mathrm{Cl}_{2} / \mathrm{CCl}_{4}$ carrier gas, $\Delta E i^{*}(x)$ : calculated with $\Delta S_{\text {ads }}$ for simple adsorption of $\mathrm{CoCl}_{2}$;

$T$ : experimental deposition temperature in $\mathrm{Cl}_{2} / \mathrm{CCl}_{4}$ carrier gas, $\Delta E i^{*}(x)$ : calculated with $\Delta S_{\text {dissads }}$ for dissociative adsorption of $\mathrm{CoCl}_{3}$. d) $\mathrm{RuCl}_{3}-\mathrm{RuCl}_{4}$ [5]: $+T$ : experimental deposition temperature in $\mathrm{Cl}_{2}-\mathrm{CCl}_{4}$ carrier gas, $E i^{*}(x)$ : calculated with $\Delta S_{\text {ads }}$ for simple adsorption of $\mathrm{RuCl}_{3}$; $T$ : experimental deposition temperature in $\mathrm{Cl}_{2}-\mathrm{CCl}_{4}$ carrier gas, $\Delta E i^{*}(x)$ : calculated with $\Delta S_{\text {diss.ads }}$ for dissociative adsorption of $\mathrm{RuCl}_{4}$, e) $\mathrm{CeCl}_{3}-\mathrm{CeCl}_{4}$ : + [1] $T$ : experimental deposition temperature in $\mathrm{Cl}_{2} / \mathrm{CCl}_{4}$ carrier gas, $\Delta E i^{*}(x)$ : calculated with $\Delta S_{\text {ads }}$ for simple adsorption of $\mathrm{CeCl}_{3} ; \bullet$ [5] $T$ : experimental deposition temperature in $\mathrm{Cl}_{2}-\mathrm{CCl}_{4}$ carrier gas, $\Delta E i^{*}$ $(x)$ : calculated with $\Delta S_{\text {diss.ads }}$ for dissociative adsorption of $\mathrm{CeCl}_{4} ;-$ [20] $T$ : experimental deposition temperature in $\mathrm{N}_{2} / \mathrm{Cl}_{2}$ carrier gas (high temperature peak), $\Delta E i^{*}(x)$ : calculated with $\Delta S_{\text {ads }}$ for simple adsorption of $\mathrm{CeCl}_{3}$; experimental deposition temperature in $\mathrm{N}_{2} / \mathrm{Cl}_{2}$ carrier gas (low temperature peaks), $\Delta E i^{*}(x)$ : calculated with $\Delta S_{\text {diss.ads }}$ for dissociative adsorption of $\mathrm{CeCl}_{4}$. 


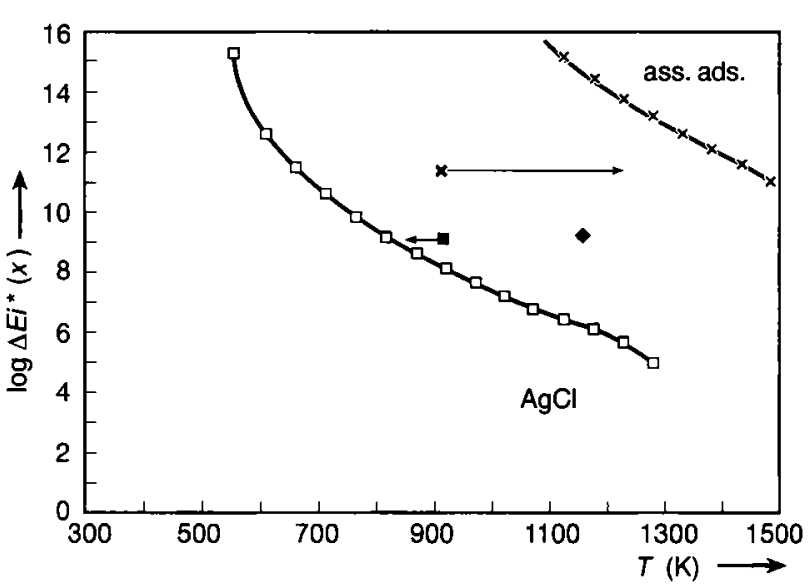

Fig. 2. Deposition temperature in thermochromatographic column - comparison between experimental and calculated data for a simple or an associative adsorption reaction of $\mathrm{AgCl}$. $\mathbf{0}$ [5] $T$ : experimental deposition temperature in $\mathrm{Cl}_{2}-\mathrm{CCl}_{4}$ carrier gas, $\Delta E i^{*}(x)$ : calculated with $\Delta S_{\text {ads }}$ for simple adsorption of $\mathrm{AgCl}$; $\times$ [5] $T$ : experimental deposition temperature in $\mathrm{Cl}_{2} / \mathrm{CCl}_{4}$ carrier gas, $\Delta E i^{*}(x)$ : calculated with $\Delta S_{\text {ass.ads }}$ for associative adsorption of $\left(\mathrm{Ag}+1 / 2 \mathrm{Cl}_{2} \rightarrow \mathrm{AgCl}\right)$; $\bullet$ (21) $T$ : experimental deposition temperature in $\mathrm{H}_{2}$ carrier gas, $\Delta E i^{*}(x)$ : calculated with $\Delta S_{\text {ads }}$ for simple adsorption of $\mathrm{Ag}$

$\mathrm{CeCl}_{4}$ was not noticed in $[17,18]$. In condensed state, $\mathrm{CeCl}_{4}$, like $\mathrm{PuCl}_{4}$, does not exist. It is possible that the adsorbed state of $\mathrm{CeCl}_{3}$ at low coverage favours the chlorination process.

\subsection{Associative adsorption}

In the case of $\mathrm{AgCl}$, compared to correlation (1), a higher deposition temperature was observed [5]. Therefore, it was investigated, whether the results can be explained by an associative adsorption process:

$$
\mathrm{Ag}(\mathrm{g})+1 / 2 \mathrm{Cl}_{2}(\mathrm{~g}) \leftrightarrow \mathrm{AgCl} \text { (ads). }
$$

This assumption is based on the high degree of dissociation of silver halides in the gas phase. In a process of this type, the large value of the adsorption entropy (strong reduction of the number of gaseous particles) would also lead to a relatively high deposition temperature.

Figure 2 shows the calculated curve for the adsorption process of $\mathrm{AgCl}$ and the associative adsorption process. The experimental result favours a simple adsorption process.

Comparison with an experimental value for $\mathrm{Ag}$ (in hydrogen carrier gas [21]) shows, that a separate $\mathrm{Ag}$ adsorption process cannot be postulated. The reasons for the deviating behaviour of $\mathrm{AgCl}$ from that calculated are probably due to experimental shortcomings (e.g. reducing contaminants, etc.).

\subsection{Substitutive adsorption}

Chlorinating carrier gases are practically never free of contaminants, e.g. oxygen. For this reason it is useful

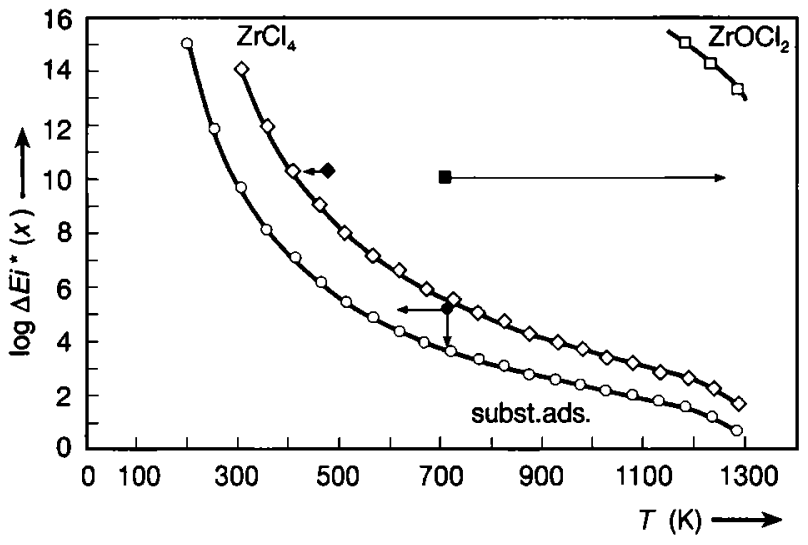

Fig. 3. Deposition temperature in thermochromatographic column - comparison between experimental and calculated data for a simple or an substitutive adsorption reaction of $\mathrm{ZrCl}_{4}$ $\mathrm{ZrOCl}_{2}$ [24]. $-T$ : experimental deposition temperature in $\mathrm{N}_{2} /$ $\mathrm{SOCl}_{2}$ carrier gas, $\Delta E i^{*}(x)$ : calculated with $\Delta S_{\text {ads }}$ for simple adsorption of $\mathrm{ZrCl}_{4} ; \mathbf{\square}$ : experimental deposition temperature in $\mathrm{N}_{2} / \mathrm{SOCl}_{2} / \mathrm{O}_{2} / \mathrm{N}_{2}$ carrier gas, $\Delta E i^{*}(x)$ : calculated with $\Delta S_{\text {ads }}$ for simple adsorption of $\mathrm{ZrOCl}_{2}$; $T$ : experimental deposition temperature in $\mathrm{N}_{2} / \mathrm{SOCl}_{2} / \mathrm{O}_{2} / \mathrm{N}_{2}$ carrier gas, $\Delta E i^{*}(x)$ : calculated with $\Delta S_{\text {substads }}$ for substitutive adsorption of $\mathrm{ZrCl}_{4}$ $\left(\mathrm{ZrCl}_{4}+1 / 2 \mathrm{O}_{2} \rightarrow \mathrm{ZrOCl}_{2}+\mathrm{Cl}_{2}\right)$.

to investigate system, which have a tendency for substitution reactions, due to their "sensitivity" to oxygen. As an example, zirconium, which has often been experimentally investigated, was selected. Usually thermochromatographic results in chlorinating carrier gases with carrier-free $\mathrm{Zr}$ nuclides are associated with a chromatographic process involving $\mathrm{ZrCl}_{4}$.

If oxygen is added to the carrier gas, a significant increase in the deposition temperature occurs compared to the above mentioned process [22-24]. In this case, it seems evident to postulate a chromatographic process involving gaseous $\mathrm{ZrOCl}_{2}$. However, this interpretation is obviously incorrect because of the nonexistence of $\mathrm{ZrOCl}_{2}$ in the gas phase. $\mathrm{ZrOCl}_{2}$ can be prepared in a gas-solid reaction [23]. However, this does not prove that $\mathrm{ZrOCl}_{2}$ is invariantly present in the gas phase or in the gas adsorption chromatographic process.

Rather, another type of reaction must be taken into account - the substitutive adsorption:

$$
\mathrm{ZrCl}_{4}(\mathrm{~g})+1 / 2 \mathrm{O}_{2} \leftrightarrow \mathrm{ZrOCl}_{2} \text { (ads) }+\mathrm{Cl}_{2}(\mathrm{~g})
$$

This is supported by the thermochemical estimate with Eqs. (6) and (7) (see Table 1). According to this, $\mathrm{ZrOCl}_{2}$ is a "non volatile" compound. $\mathrm{ZrOCl}_{2}$ cannot be volatilized from pure condensed systems. The decomposition temperature lies between 335 and $370^{\circ} \mathrm{C}$ [25]. Due to the large, hypothetical sublimation enthalpy of $\mathrm{ZrOCl}_{2}$, a high adsorption enthalpy must be expected. This leads to theoretical deposition temperatures far above the decomposition temperature.

Starting from the estimates in Table 1 and from tabulated data [1-15], the enthalpy and entropy of the substitutive adsorption were calculated and the theoretical curve (subst.ads) in Figure 3 was computed. 


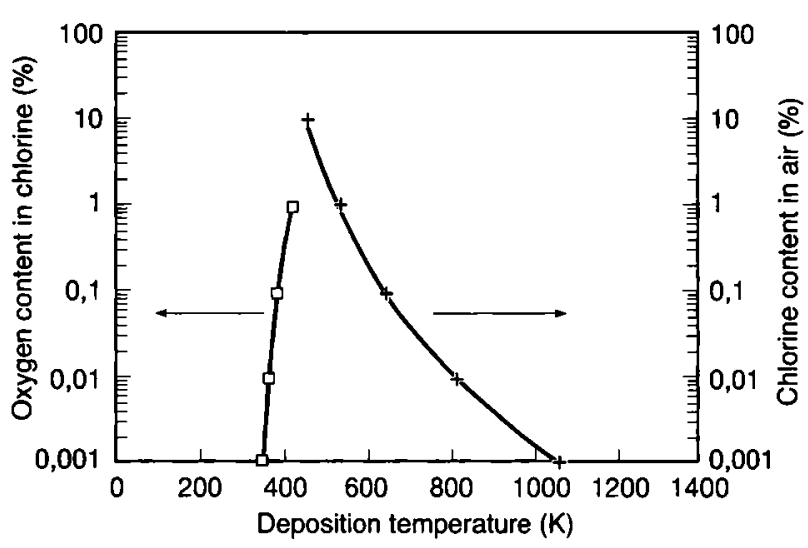

Fig. 4. Influence of the carrier gas composition $\left(\mathrm{Cl}_{2} / \mathrm{O}_{2}\right)$ to the deposition temperature of carrier-free $\mathrm{Zr}$ in the temperature gradient tube - calculations with the model of substitutive adsorption.

The experimental result [24] in the $\mathrm{N}_{2} / \mathrm{SOCl}_{2}$ carrier gas agrees well with the adsorption of $\mathrm{ZrCl}_{4}$.

The result in oxygen-containing carrier gas (the concentration of chlorine was calculated assuming the complete dissociation of the $\mathrm{SOCl}_{2}$ ) however, deviates from the theoretical curve for substitutive adsorption.

The coarse methods for estimating the thermochemical data lead to a considerable absolute error, which has a strong effect, especially for small absolute values for $\Delta H$ (subst.ads).

The composition of the gas phase has a great influence on the gas adsorption chromatographic process of $\mathrm{Zr}$. As demonstrated in Figure 4, the influence of oxygen concentration in the chlorine carrier gas or the chlorine content in a carrier gas with $20 \%$ oxygen, respectively, on the deposition temperature was calculated for conditions analoguous to those in experiment [24].

There seems to be a high sensitivity of the deposition position to the composition of the carrier gas.

\section{Conclusions}

The comparison of measured data from gas adsorption chromatographic experiments with thermochemical model calculations for various basic processes of the chromatographic transport allows the determination of the type of adsorption reaction, which governs the chromatographic process.

The discussed complex processes deviate fundamentally from the simple adsorption processes with invariant species. Their profound influence must be taken into account when evaluating gas adsorption chromatographic experiments and determining the adsorption enthalpy or when deriving the chemical state of the carrier-free nuclide.

From experimental data thermochemical values can be approximated if the type of the adsorption reaction can unambiguously be identified. The knowledge of the type of reaction is of eminent importance for the evaluation of the migration velocity of a substance in the column, especially in experiments with shortlived radionuclides.

The shapes of the calculated curves in Figures 14 demonstrate that substances with high values for $\Delta H_{\text {ads }}$ (see Table 1) at high temperatures migrate slowly but steadily. In contrast, substances with small values of $\Delta H_{\text {ads }}$ quickly reach the region of their deposition temperature and then move only very little. This is valid for simple adsorption reactions.

By superimposing a chemical reaction, significant changes occur in the entropy of the gross process. The entropy change in dissociative adsorption processes is substantially smaller than in the case of simple adsorption.

For the same adsorption enthalpy significantly lower deposition temperatures are observed with the simple adsorption reaction compared to a dissociative adsorption process under the same conditions.

The results permit practical conclusions for the interpretation of gas adsorption chromatographic experiments: The preparation of a pure chloride and the characterization of its gas chromatographic behaviour, requires the addition of an internal oxygen getter. This way, the substitution with oxygen can be eliminated. This measure is unavoidable if the substitution is thermodynamically possible.

The unambiguous interpretation of the results of experiments on the basis of dissociative adsorption processes of chlorides in higher oxidation state require stable, known, chlorine concentrations in the carrier gas. If experiments involving a substitutive adsorption mechanism are planned, the chlorine and oxygen concentrations must be well defined.

Accounting for superimposed chemical reactions has wide-ranging consequences in determining the chemical state and the characterization of the volatility of chlorides or oxychlorides of carrier-free radionuclides, e.g. the transactinides, with gas adsorption chromatographic methods.

\section{Literature}

1. Merinis, J., Bouissieres, G.: Radiochim. Acta 12(3), 139 (1969).

2. Eichler, B., Zvara, I.: Radiochim. Acta 30, 233 (1982).

3. Eichler, B., Zude, F., Fan, W., Trautmann, N., Herrmann, G.: Radiochim. Acta 61, 81 (1993).

4. Leipnitz, E., Struppe, H. G.: Handbuch der Gaschromatographie. Verlag Chemie, Weinheim 1970.

5. Eichler, B., Domanov, V. P., Zvara, I.: Preprint JINR P129454, Dubna 1976.

6. Dudchik, G. P., Polyachenok, O. G., Novikov, G. I.: Russ. J. Phys. Chem. 45(3), 409 (1971).

7. Knacke, O., Kubaschewski, O., Hesselmann, K.: Thermochemical properties of inorganic substance, Springer-Verlag und Verlag Stahleisen Düsseldorf 1991.

8. Barin, I., Knacke, O.: Thermochemical properties of inorganic substances (Supplement), Springer-Verlag, Berlin 1977.

9. Effimov, A. I.: Svoistva neorganiceskikh sojedinenie, Izd. Khimiya, Leningrad 1983.

10. Samsonov, G. V.: Svoistva elementov, Izd. Metallurgiya Moskva 1976. 
11. Kubaschewski, O.: Atomic Energy Review, Special Issue Nr. 9, Titanium: Physico-chemical Properties of its Compounds and Alloys. IAEA, Vienna 1983.

12. Alcock, C. B., Jacob, K. T., Zador, S.: Atomic Energy Review Special Issue Nr. 6, Zirconium: Physico-chemical Properties of its Compounds and Alloys, IAEA, Vienna 1976.

13. Dellien, I., Hall, F. M., Heppler, L. G.: Chem. Rev. 76(3), 283 (1976).

14. Karapetjanz, M. Kh.: Osnovie Termodinamiceskie Konstan$t i$, Izd. Khimiya, Leningrad 1983.

15. Gurvic, L. B.: Energija Razriva Khimiceshkikh Svjazei, Izd. Nauka, Moskva 1974.

16. Merinis, J., Legoux, Y., Bouissieres, G.: Radiochem. Radioanal. Letters 3(4), 255 (1970).

17. Bayanov, A. P., Frolov, Yu. A.: Zhurn. Fiz. Khim. 51, 1567 (1977)

18. Travnikov, S. S., Davydov, A. V., Mysoedov, B. F.: J. Radioanal. Chem. 25, 17 (1975).

19. Dienstbach, F., Baechmann, K.: Radiochim. Acta 34, 215 (1983).
20. Hickmann, U., Greulich, N., Trautmann, N., Gäggeler, H., Gäggeler-Koch, H., Eichler, B., Herrmann, G.: Nucl. Instrum. Methods 174, 507 (1980).

21. Eichler, B.: Kernenergie 19(10), 307 (1976).

22. Domanov, V. P., Kim, U. Zin: Radiokhimiya 31(2), 19 (1989).

23. Domanov, V. P., Kim, U. Zin, Bergonosov, S. S., Kopilova, I. A., Lebedev, V. Ja.: Zhum. Neorg. Khim. 35(1), 20 (1990).

24. Bruchertseifer, F., Türler, A., Eichler, B., Gäggeler, H. W., Jost, D. T.: PSI Annual Report, Annex F3A (1993).

25. Eichler, B.: Herstellung von reinem wasserfreien Plutonium(III)-chlorid durch Chlorierung mit Tetrachlorkohlenstoff und Verflüchtigung im Chlorstrom. ZfK-191, Rossendorf 1969.

26. Morozov, A. I., Karlova, E. V.: Russ. J. Inorg. Chem. 16(1), 12 (1971).

27. Schäfer, H.: Chemische Transportreaktionen. Monographien zu „Angewandte Chemie“ und „Chemie-Ingenieur-Technik" Nr. 76, Verlag Chemie, Weinheim 1962. 